\title{
First report of Taenia pisiformis Cysticercus infestation in Domestic rabbits in Hajjah city
} Yemen

Received: 02 November, 2020

Accepted: 30 November, 2020

Published: 01 December, 2020

*Corresponding author: Nabil M Mogalli, Department of Biology, Hajjah University, Yemen, Tel: 00967772423369; E-mail: nabilmogalli@yahoo.com

ORCID: https://orcid.org/0000-0002-1845-986X

Keywords: Taenia pisiformis; Cysticercosis; Histopathology; Rabbit; Yemen

https://www. peertechz.com

Check for updates

\section{Nabil M Mogalli*}

Department of Biology, Hajjah University, Yemen

\begin{abstract}
Cysticercus pisiformis is larval forms of Taenia pisiformis tapeworm. thas been observed in rabbits that are considered the intermediate host. In this study Cysticercus pisiformis was observed in domestic rabbits at routine necropsy examination. Cysticercus pisiformis was observed in 23 (76.7) out of 30 (23.3\%) of domestic rabbits of both sexes was 2 months - 2 years old. the Parasites were observed only in July2018 and February 2020. After noticing the changes in the shape of the liver, which appeared in white to cream cysts were ranging from $3-8 \mathrm{~mm}$ in diameter and varying in sizes, The aim of this study was to identify, which is the causative of these changes in the liver and the nature of cysts developing around the stomach and what organisms belong to them, as well as the preparation of tissue sections of the liver to study histopathological changes. Our results revealed, several cysts were found around the stomach and viscera. morphological form of these cysts depicted the presence of Cysticercus pisiformis of Taenia pisiformis and the larval stage was also seen moving near the diaphragm. Gross and histopathological examination revealed that liver was the most severely affected organ. Varying degrees of focal necrosis, hepatocellular degeneration, inflammation associated with viable and degenerated cysts were observed in the liver. Degenerated cysts revealed varying degrees of dystrophic calcification. Our results revealed, (23) were infected (76.6\%) of Cysticercus pisiformis of adult parasite Taenia pisiformis it is the first report in Hajjah / Yemen.
\end{abstract}

\section{Introduction}

Rabbits are mammals, found in in many regions of the world. Rabbits are infected with a range of parasites varying from ectoparasites, protozoans, and helminths.

Parasites infesting Rabbits lead to large losses in rabbits, and those losses are related to the number of parasites responsible for the disease [1].

Helminth infection causes greater bifurcation with a significant effect on this animal, when present in a sufficient number, it can cause a significant decrease in weight gain, loss of appetite, diarrhea, weakness, low productivity, morbidity, and even deaths.

Protozoans infection such as Eimeria, are associated with morbidity and mortality this lead to economic losses in rabbit farming, growth retardation and condemnation of affected livers in cases of hepatic coccidiosis [2].
Cysticercus pisiformis. Which consider as Parasite on rabbit farms and it is pathogenic parasite among parasites Taenia pisiformis (Cestoidea; Cyclophyllidea; Taeniidae. Commonly called rabbit tapeworm, can be found all over the world [3,4] and it is a tapeworm parasitizes internally and causes infection and matures in the small intestine of canids and felines [5,6].

The infection is transmitted to the Rabbits (intermediate hosts) by eating the herb contaminated with the stool of the final hosts where pass the egg-laden proglottid phase in their feces. Once ingested, the egg hatches and the hexacanth embryo enters the wall of the intestine and migrates to its organ of choice via the portal veins then grows and differentiateson cavitates to form the second larval stage which consists of a fluid-filled bladder with a scolex called a cysticercus or as Cysticercus pisiformis (Schoeb, et al. 2007).This second larval stage is also often called bladderworm and forms (2-4) weeks following ingestion [7].

The cysticercus stage encysts on the liver capsule or other abdominal serosal surfaces (Schoeb, et al. 2007) and can cause 
severe health problems in rabbits, such as digestive disorders, and secondary bacterial infestation, liver lesions, resulting in economic losses in the rabbit breeding industry [8]. Cysticercus pisiformis is swallowed by the definitive host when it feeds on the infected organs of rabbits with C. pisiformis [9].

Parasitism is of great concern to the production, reproduction and performance of man and animals (Shola D, et al. 2018) infection with T. pisiformis altered behavioral and productive parameters, and obesity magnifies the impact caused by the infection. Also, obesity leads to major susceptibility to infection with T. pisiformis [10]. Infected with T. pisiformis metacestodes are more frequently in female rabbits than males [11].

This study appears to be the first to be conducted in the northwestern part of Yemen. As these parasites have not been documented before in northwestern Yemen. Proper management of the prevention, control and elimination of these diseases will improve rabbit production and reproduction to achieve better profitability for farmers and increase the availability of protein sources for consumers.

The aim of this study was to determine the cause of the altered changes in the liver and the nature of the cysts that develop around the stomach and what organisms they belong to, as well as preparing sections of liver tissue to study tissue changes.

\section{Materials and methods}

In July2018 and February 2020, when we were working on anatomy of rabbits, we found calcifications in the liver and cysts around the stomach and moving larvae. in most rabbits that were studied. and after research and investigation we know it is Cysticercus pisiformis.

Cysticercosis was studied in Domestic rabbits. Gross lesions were noted. Tissue pieces from liver were collected and fixed in $10 \%$ formalin, embedded in paraffin wax, and fivemicron sections were stained with haematoxylin and eosin (H\&E) for histological examination. Histological sections of tissues with the most interesting findings were photographed. Photomicrograph was done using cell phone and OLYMPUS microscope CX31.

\section{Results}

\section{Clinical history}

The rabbits suffered from xanthoderma prolonged illness with depression, weakness and palour of mucous membranes.

\section{Necropsy findings}

On necropsy, 23 rabbits revealed cystic disease. the external mucous membranes were pale. Several oval cysts (varying sizes from $6 \mathrm{~mm}$ to $1 \mathrm{~cm}$ ) were found either attached to the omentum to form of clusters, between the diaphragm and the viscera and visceral surfaces of liver or floating free in the peritoneal cavity. Each cyst contained clear fluid and a single white spot. Cysts were identified as the Taenia pisiformis cyst Figure 1.

The liver was firm and contained scattered creamish to white in colour and ranged from $3-18 \mathrm{~mm}$ in diameter, interspersed with prominent white streaks (width, 2 to $4 \mathrm{~mm}$ ) Some livers of rabbits appear to have shapes in the form of spots distributed in different parts of the liver, while others have large areas or fusiform spots that show a change in color and shape (Figure 2).

Moving larvae of T. pisiformis were observed in infected rabbits in different numbers in the abdominal cavity between the viscera and around the stomach and the side of the diaphragm and liver, which appeared in white color length of 1 $\mathrm{cm}$ (Figure 3). The larvae was also observed at the beginning of the encystation phase on the stomach serosal surfaces Figure 4.
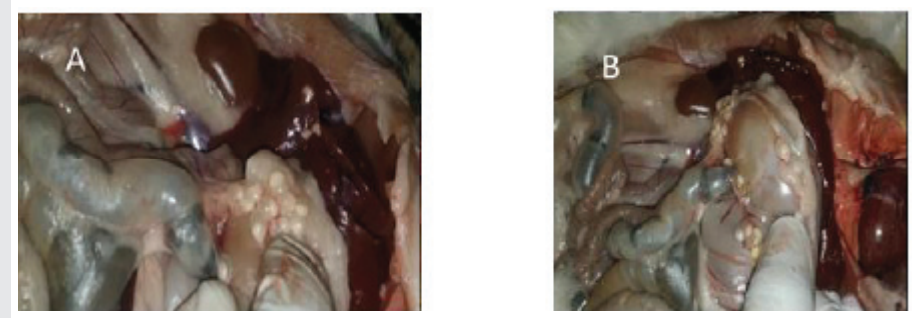

Figure 1: Multifocal hepatic cysts (arrows) contain 23 cysts of cysticercus pisiformis $A$, and eight $B$

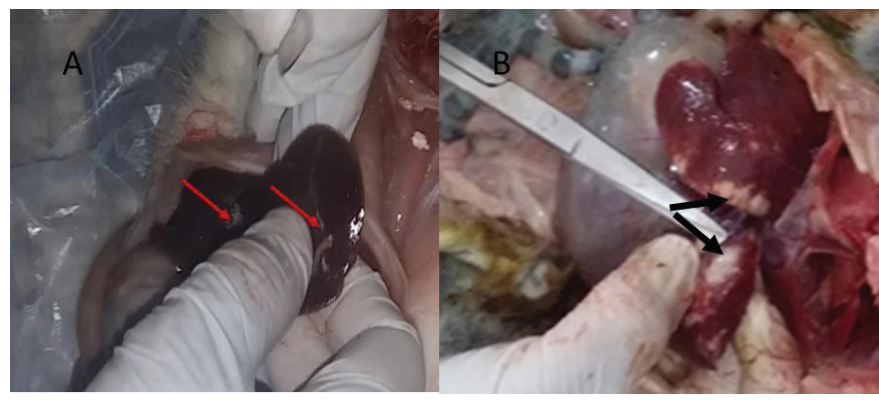

Figure 2: White spots in the liver of rabbits caused by Taenia pisiformis larvae. $A$. Liver with two spots in different lobes B. fusiform spots in the liver

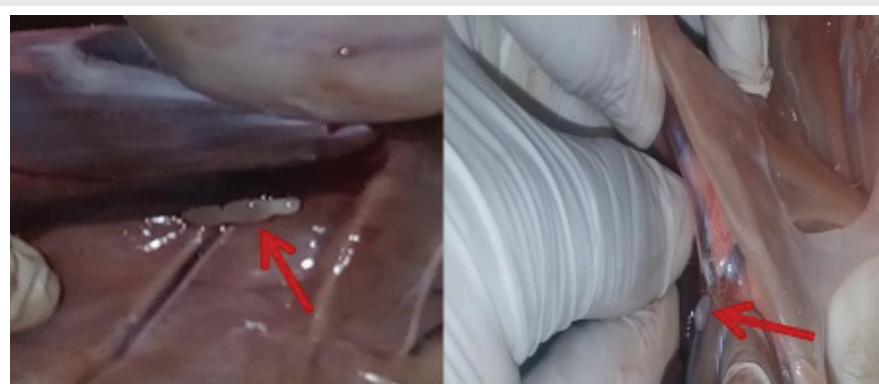

Figure 3: Larva of Taenia pisiformis

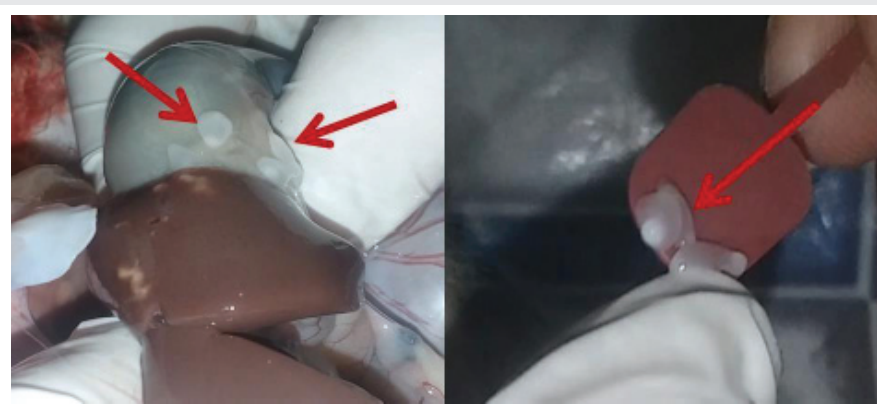

Figure 4: Larvae at the beginning of the encystation on the stomach serosa surfaces, B. Larvae after removed from the stomach serosal surfaces 


\section{Microscopic findings}

The liver revealed varying degrees of hepatitis, hepatic cellular degeneration, and necrosis. Degenerative changes ranged from cellular / cloudy swelling to eosinophilia with cytoplasmic granulation and spatial changes. Subsequently, the nucleus of the hepatocytes was compressed toward the periphery, and the cytoplasm is represented by one peripheral margin.

Multifocal areas of focal hepatic necrosis were observed with aggregation of lymphocytic and infiltration also, a few macrophages and giant cell Figure 5.

Most of the spaces were empty and has hepatocellular degradation and fatty changes have also been observed, steatosis and fatty degeneration Figure 6.

Hyperplasia was also detection in the biliary duct of the liver Figure 7.

\section{Discussion}

In most rabbits that were studied in July 2018 and February 2020, when performing routine anatomy of rabbits, calcifications were found in the liver and cyst hanging around the stomach and viscera, and larvae were also seen moving in the abdominal cavity.. The reason for this was due to rabbits being infected with Cysticercus pisiformis of T. pisiformis parasites.

Our results revealed the present of Cysticercus pisiformis in $23(76.7)$ out of $30(23.3 \%)$ of domestic rabbits which consider

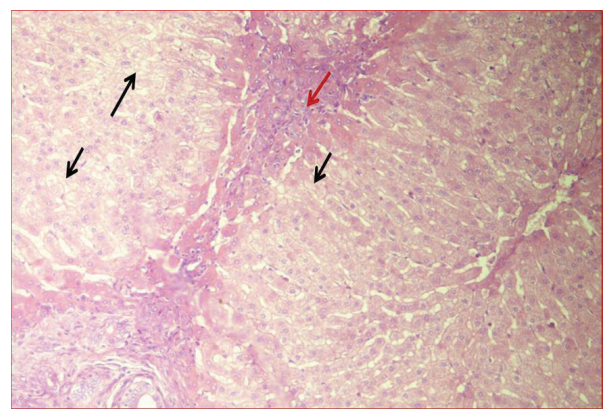

Figure 5: Photomicrograph from rabbit's liver showing focal hepatic necrosis (black arrow) and infiltration in lymphocytic of liver tissues (red arrows) (Heamatoxylin and Eosin 40X)

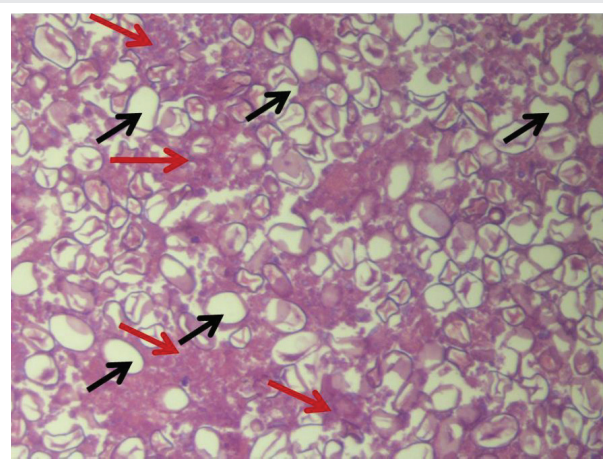

Figure 6: Photomicrograph from rabbit's liver showing steatosis and fatty degeneration (black arrow) and hepatocellular degradation (red arrows) (H E 40X).

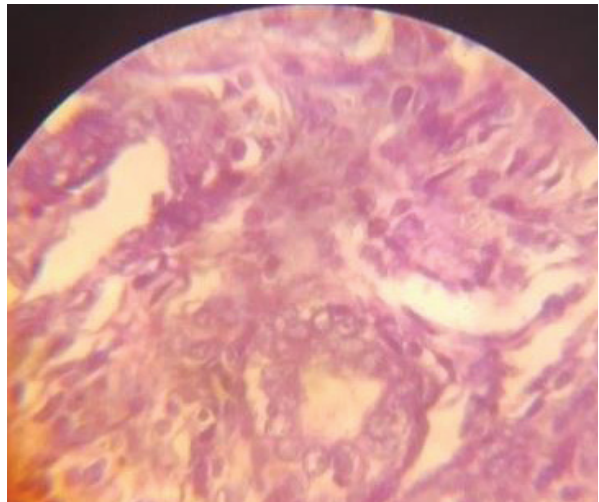

Figure 7: Hyperplasia of the epithelial cells of the biliary duct in liver infected rabbits (H E 40X).

one of the phases of Taenia pisiformis tapeworm that has not been documented in Yemen and neighboring country also there is no published study on infection in domestic or wild rabbit available in Yemen. then the percent study is the first study of T. pisiformis in yemen.

In this study the Cysticercus pisiformis have been observed in rabbits in specific periods of the year they were represented in the spring between July and February.

Several oval cysts were found attached to different site of abdominal cavity this is consistent with many of the reports M.S. Mir, et al. 2006.

Which migrated through the parenchyma and then enter the abdominal cavity where it is attached to the serous surfaces (smyth, JD et al. 1998). The most common clinical symptom is the presence of mature cysticerci within the abdominal cavity the results are considered accidental, if the infection is not severe, as mentioned by [12].

The metacestode of T. pisiformis has been considered one of the most important true migratory parasites in rabbits with an infection rate of 2.2 to $51.3 \%$ in commercial / domestic rabbits $[13,14]$. and female rabbits are more frequently infected with $T$. pisiformis metacestodes than males [11].

Oval cysts were found attached to the omentum to form of clusters, between the diaphragm and the viscera and visceral surfaces of liver or floating free in the peritoneal cavity the observations in this study are consistent with those of Singh, et al. [15] and Myers, et al. 2006 who reported a vesicular cyst attached to the viscera, as well as floating in the peritoneum [15].

The severity of the affected was varied in the liver that occur due to entry of oncospheres Mir m s, et al. (2006) mentions to a relationship between the liver and the development and migration of the Taenia pisiformis metacestodes. When examining the morphological infected liver in our study, the liver was enlarged with multiple linear fibrous tracks and it was found that the rabbits that have a severe infection, the liver was changing in color and contains a large area of the Vesicles, while rabbits that have a slight infection the color change and the area of infection was few.

Citation: Mogalli NM (2020) First report of Taenia pisiformis Cysticercus infestation in Domestic rabbits in Hajjah city Yemen. Int J Vet Sci Res 6(2): 159-163. DOI: https://dx.doi.org/10.17352/ijvsr.000068 
Similar changes have been reported by Kumar, et al. [16]; Singla, et al. [17] who indicated that the metacestode stage caused significant hepatic destruction and gastroenteropathy in intermediate host $[16,17]$.

Histopathological study, it was revealed that there was tissue damage in the liver. After a microscopic examination, it was found that there was showed numerous discrete to coalescing granulomas containing substantial intact and degenerate parasites This was similar to Graham-Brown J, et al. [18] observations [18]. Also there was cellular and fatty degradation and infiltration which is in confirm with Singla's, et al. [19] Al-Najjar, et al. [20] and Aman D Moudgil, et al. 2016 [21] observation. Their histopathological study of the affected liver showed the presence of fatty changes and infiltration of mononuclear cells in the affected zones [19-28].

\section{Conclusion}

In the present study, the presence of cysticercus pisiformis in 30 Domestic rabbits was investigated. It was observed that the infected rabbits were 23 rabbits. It was determined by noticing the presence of cysts, larvae, or even pathological changes in liver tissue Cysticerci were found to be present in varying numbers hanging to the viscera or around of the stomach also the larvae have been observed moving in the abdominal cavity and some have penetrated the gastric membrane of the stomach. histopathological study showed several separate granulomas that contain large, intact and degraded amounts. This study is the first report on Taenia pisiformis parasites in Yemen. In the upcoming studies, it is necessary to investigate and survey the pathogenic parasites that infective rabbits. Surveys must be done to identify the types of animals that act as definitive host for Taenia pisiformis.

\section{Acknowledgement}

The authors are thankful to the Department of Medical Laboratory technology College of Ibn Hayan of Medical Science and Technology Republic of Yemen.

\section{References}

1. Rewatkar SG, Deshmukh SS, Kumar PG, Maske DK, Bhangale GN (2013) Occurrence of Gastrointestinal Helminths in rabbits with special Reference to Importance of Giardia spp. as Parasitic Zoonoses. Science Technology and Arts Research Journal 2: 142-143. Link: https://bit.ly/2Vi2Tzo

2. Darzi MM, Mir MS, Kamil SA, Nashiruddullah N, Munshi ZH (2007) Pathologica changes and local defense reaction occurring in spontaneous hepatic coccidiosis in rabbits (Oryctolagus cuniculus). World Rabbit Science 15: 2328. Link: https://bit.ly/3fSvbda

3. Martínez-Moreno FJ, Hernánde S, López-Cobos E, Becerra C, Acosta I, et al. (2007) Estimation of canine intestinal parasites in Cordoba (Spain) and their risk to public health. Vet Parasitol 143: 7-13. Link: https://bit.ly/3fSXSGK

4. Coman BJ, Rickard MD (1975) The location of Taenia pisiformis, Taenia ovis and Taenia hydatigena in the gut of the dog and its effect on net environmental contamination with ova. Zeitschrift für Parasitenkunde 47: 237-248. Link: https://bit.ly/3ohxFVD

5. Bagrade G, Kirjusina M, Vismanis K, Ozolins J (2009) Helminth parasites of the wolf Canis lupus from Latvia. Journal of Helminthology 83: 63-68. Link: https://bit.ly/33wA6M5
6. Jia WZ, Yan HB, Guo AJ, Zhu XQ, Wang YC, et al. (2010) Complete mitochondrial genomes of Taenia multiceps, $\mathrm{T}$. hydatigena and T. pisiformis: additional molecular markers for a tapeworm genus of human and animal health significance. BMC Genomics 11: 447. Link: https://bit.ly/3mqY9Dv

7. Foronda P, Valladares B, Lorenzo-Morales J, Ribas A, Feliu C, et al. (2003) Helminths of the wild rabbit (Oryctolagus cuniculus) in Macaronesia. $J$ Parasitol 89: 952-957. Link: https://bit.ly/2JtHCQv

8. Zhou YX, Du AF, Zhang XJ, Wu YM, Tong FY, et al. (2008) Research of harmfulness of Cysticercus pisiformis in rabbit. Journal of Zhejiang Agricultural Science 3: 372-373.

9. Sun X, Luo X, Wang X, Cai XP (2008) Observation of the organizational structure of Cysticercus pisiformis and Taenia pisiformis scolex. Chinese Veterinary Science 38: 796-800. Link: https://bit.ly/3lmWoWt

10. Arias-Hernández D, Flores-Pérez FI, Domínguez-Roldan R, Báez-Saldaña $A$ Carreon RA, et al. (2019) Influence of the interaction between cysticercosis and obesity on rabbit behavior and productive parameters. Vet Parasitol 276 108964. Link: https://bit.ly/39vhfoc

11. Domínguez-Roldan R, Pérez-Martínez M, Rosetti MF, Arias-Hernández D, Bernal-Fernández G, et al. (2018) High frequency of Taenia pisiformis metacestodes and high sex-associated susceptibility to cysticercosis in naturally infected wild rabbits. Parasitol Res 117: 2201-2206. Link: https://bit.ly/3o8ZsY8

12. Varga M (2014) The rabbit-friendly practice. In BSAVA manual of rabbit medicine. BSAVA Library 59-79. Link: https://bit.ly/33wCwdu

13. Flatt RE, Campbell WW (1974) Cysticercosis in rabbits: incidence and lesions of the naturally occurring disease in young domestic rabbits. Lab Anim Sci 24 914-918. Link: https://bit.ly/3fX5nMX

14. Lavicka M, Zajicek D (1988) Occurrence and diagnostics of larval stages of tapeworm in the liver of rabbits. Veterinarni Medicina-UVTIZ (Czechoslovakia). Link: https://bit.ly/3mprQ7L

15. Singh D, Gulyani R, Bhasin V (1992) Cysticercus pisiformis in commercial rabbits. Indian Vet Med J 16: 71

16. Kumar JM, Reddy PL, Aparna V, Srinivas G, Nagarajan P, et al. (2006) Strobilocercus fasciolaris infection with hepatic sarcoma and gastroenteropathy in a Wistar colony. Vet Parasitol 141: 362-367. Link: https://bit.ly/3mpP1Pt

17. Singla LD, Singla N, Parshad VR, Juyal PD, Sood NK (2008) Rodents as reservoirs of parasites in India. Integr Zool 3: 21-26. Link: https://bit.ly/3o7RmPx

18. Graham-Brown J, Gilmore P, Harcourt-Brown F, Eastham H, Williams D (2018) Lethal cysticercosis in a pet rabbit. Veterinary Record Case Reports 6. Link: https://bit.ly/2VkLmGD

19. Singla LD, Singla N, Parshad VR, Sandhu BS, Singh J (2003) Occurrence and pathomorphological observations of Cysticercus fasciolaris in lesser bandicoot rats in India. Aciar Monograph Series 96: 57-60. Link: https://bit.ly/33w0sNX

20. Moudgil AD, Singla LD, Gupta K, Daundkar PS, Vemu B (2016) Histopathological and morphological studies on natural Cysticercus fasciolaris infection in liver of Wistar rats. J Parasit Dis 40: 255-258. Link: https://bit.ly/2Viopnw

21. Al-Najjar SS, Kadhim FS, Abdalrziak NA (2009) Parasitological and Pathologica study of the Cysticercus fasciolaris that are naturally infest white mice. AlAnbar Journal of Veterinary Sciences 2: 43-47. Link: https://bit.ly/2Vj49SD

22. Baker GD (2007) Flynns parasite of laboratory animals. Blackwell Publishing USA 51-68. Link: https://bit.ly/3oclvNz

23. Loos-Frank B (2000) An up-date of Verster's (1969) Taxonomic revision of the genus Taenia Linnaeus'(Cestoda) in table format. Syst Parasitol 45: 155-183. Link: https://bit.ly/36peRxj 
24. Ola-Fadunsin SD, Hussain K, Rabiu M, Ganiyu IA (2018) Parasitic conditions of domestic owned rabbits in Osun State, southwestern Nigeria: Retrospective evaluation, risk factors and co-infestations. Int J Vet Sci Med 6: 208-212. Link: https://bit.ly/2VibmCJ

25. Rajasekariah GR, Rickard MD, O'donnell IJ (1985) Taenia pisiformis: protective immunization of rabbits with solubilized oncospheral antigens. Experimental Parasitology 59: 321-327. Link: https://bit.ly/3lu4KLT

26. Smyth JD, Wakelin D (1994) Introduction to animal parasitology. Cambridge university press. Link: https://bit.ly/309x0W3
27. Toral-Bastida E, Garza-Rodriguez A, Jimenez-Gonzalez DE, Garcia-Cortes R, Avila-Ramirez G, et al. (2011) Development of Taenia pisiformis in golden hamster (Mesocricetus auratus). Parasites \& vectors 4: 1-4. Link: https://bit.ly/3lo2ea7

28. Harcourt-Brown F (2002) Infectious diseases of domestic rabbits. Textbook of rabbit medicine 361. Link: https://bit.ly/36pcjPR

\section{Discover a bigger Impact and Visibility of your article publication with}

\section{Peertechz Publications}

\section{Highlights}

* Signatory publisher of ORCID

* Signatory Publisher of DORA (San Francisco Declaration on Research Assessment)

* Articles archived in worlds' renowned service providers such as Portico, CNKI, AGRIS, TDNet, Base (Bielefeld University Library), CrossRef, Scilit, J-Gate etc.

* Journals indexed in ICMJE, SHERPA/ROMEO, Google Scholar etc.

- OAI-PMH (Open Archives Initiative Protocol for Metadata Harvesting)

* Dedicated Editorial Board for every journal

* Accurate and rapid peer-review process

* Increased citations of published articles through promotions

* Reduced timeline for article publication

Submit your articles and experience a new surge in publication services (https://www.peertechz.com/submission).

Peertechz journals wishes everlasting success in your every endeavours.

Copyright: $\odot 2020$ Mogalli NM. This is an open-access article distributed under the terms of the Creative Commons Attribution License, which permits unrestricted use distribution, and reproduction in any medium, provided the original author and source are credited. 